\title{
Utilization of Bacterial Foraging Algorithm for Optimization of Boost Inverter Parameters
}

\author{
G. Arunkumar'1, Dr. I. Gnanambal' ${ }^{2}$ \\ ${ }^{1}$ School of Electrical Engineering, VIT University, Vellore, India \\ ${ }^{2}$ Department of Electrical and Electronics Engineering, GCE Salem, Anna University, Chennai, India \\ Email: g.arunkumar@vit.ac.in, ignan1960@gmail.com
}

Received 25 March 2016; accepted 6 April 2016; published 9 June 2016

Copyright (C) 2016 by authors and Scientific Research Publishing Inc.

This work is licensed under the Creative Commons Attribution International License (CC BY). http://creativecommons.org/licenses/by/4.0/

(c) (i) Open Access

\section{Abstract}

This paper proposes a boost inverter model capable of coping with changes in load as well as line parameters. In order to achieve an output AC voltage higher than the input DC voltage, we can use this model consisting of a pair of DC-DC converters with a load connected differentially across them. This paper aims at developing a boost inverter that is capable of achieving a very high gain, to obtain an AC voltage of $110 \mathrm{Vrms}$ from a DC input of $36 \mathrm{~V}$. This is exceptionally beneficial in renewable energy applications, where the input voltage garnered is quite small, and in need of stepping up for commercial use or transmission. However, aside from the voltage level itself, lowering the rise time, settling time, peak overshoot and steady state error of the system is of cardinal importance in order to maintain a reliable output voltage. Closed loop control of the differentially connected DC-DC converters is necessary to determine the optimal stable operating point. This paper addresses the above concerns through optimization of the proportional and integral constants using the novel Bacterial Foraging Algorithm, ensuring operation at the required optimal stable operating point. Moreover, load/line disturbances may occur due to which the stability of output voltage may be compromised and THD value may increase to undesirable extents. In these cases, utilization of the output voltage is no longer viable for several applications sensitive to such voltage fluctuations. We have demonstrated that our proposed model is capable of restoring/reverting to the satisfactory sinusoidal waveform fashion within a single voltage cycle. The waveform results that demonstrate the resilience of our model to such disturbances are represented appropriately.

\section{Keywords}

Boost Inverter, Bacterial Foraging Algorithm, PI Controller 


\section{Introduction}

A boost inverter is one that generates a peak ac voltage higher or lower than the input dc voltage, depending on the duty cycle. The topology selected for use in this paper follows that of [1], consisting of two boost DC-DC converters. These converters produce a dc-biased sine wave at the output. The modulation of each converter is such that a phase shift of 180 is maintained between them, thereby maximizing the voltage excursion across the load. The load is connected differentially across the converters. In this paper too, a similar BI topology is utilized. The sliding mode control was used in the cited paper for the following advantage that is its robustness for plant parameter variations, which leads to steady dynamics that do not vary and steady-state response in the ideal case.

However, there has been adequate criticism of the same, published in [2] which notes its disadvantages, including the complex theory that is needed, the variable switching frequency, the lack of an inductance averagedcurrent control and a restriction on the ability to select parameter values for the controller. This prompts us to seek other modes of control and optimization such as that used in [3], which proposes an adaptive control mechanism capable of coping with unknown resistive loads. This adaptive control is accomplished by using a state observer to one side of the inverter and by measuring the state variables. Single perturbation analysis was used to measure system stability and the results were supported by simulations. This was then extended to non resistive loads too in [4]. In our model too, a closed loop feedback system is incorporated to better the system response in terms of several parameters such as peak overshoot, rise time, peak time, settling time etc. A measure of these values at any operating point provides us with insight on the stability and desirability of the response of our system.

The same adaptive control has been utilized in [5] in which a control method for Uninterrupted Power Supplies for the generation of stable limit cycles and control of oscillations is proposed. The aforementioned adaptive mechanism is used here too, to cope with load changes. From the above, we can understand that analysis and testing of the ability of the system to operate steadily despite load and/or line changes is of significant importance in describing its performance. Thus, in this paper, we have specifically analyzed system responses to both line and load disturbances and presented the results in terms of appropriate graphs and figures.

The control of switched-mode power converters (SMPC) with AC output is usually accomplished by tracking a reference signal. However, newer developments that do not require an external signal have been developed too. One such control strategy is described in [6] [7], and is known as Energy Shaping. The papers achieve control for both resistive as well as RL load systems. Control strategies that don't use a reference make the system autonomous and analysis less involved. Also synchronization with the electrical network is also possible. In this paper, we constantly monitor the output voltage across the load and compare it with a Vref for closed loop control.

The value of THD is another important concern. This can be reduced by using closed loop system and optimizing the controller gain of proportional and integral controller constants respectively such that the system response is always maintained at the optimal stable operating point. Control of the switches is done through application of pulses. The timings are decided by the PWM settings. A detailed analysis of PWM techniques can be found in [8].

Upon identifying the optimal kp and ki values using BFOA, the PWM values are accordingly modified and fed to the converter switches. A particular set of optimizing values for these parameters is obtained for a particular load. Bacterial Foraging Optimization Algorithm [9] [10] (BFOA) helps us compute the desirable parameter values. To define our optimization model, we first define a population set of bacteria and then model how they execute the various processes as will be enunciated by the following section.

A very high gain and an ability to correct the output waveform pattern to normal, stable operating fashion within a single cycle of voltage using closed loop voltage mode control incorporating the novel BFOA are the unique contributions of this paper.

Proposed system follows small signal model based voltage mode control strategy. BFOA helps us to obtain accurate values of $\mathrm{kp}$ and ki that are fed into the PI controller. For a good dynamic response, we need to obtain the solution for the optimization problem which is given by Equation (1) and Equation (2).

$$
\begin{gathered}
\text { Objective function : } F=\left(1+t_{r}\right)\left(1+t_{s}\right)\left(1+P_{o}\right)\left(1+E_{s s}\right) \\
\text { Constrained by } \alpha_{\min } \leq \alpha \leq \alpha_{\max }, \text { where } \alpha=\left\{k_{p}, k_{i}\right\}
\end{gathered}
$$




$$
\text { Fitness function }=\frac{1}{F(\alpha)}
$$

\section{Proposed BFOA Based Boost Inverter}

BFOA which is actually derived by the social foraging behavior of Escherichia coli bacteria was proposed by Kevin M. Passino. A bacterium's decision making calculus while foraging is guided by two constraints. The first is the maximum energy that it can garner get per unit time while at the same time moving in search of nutrients. The second constraint is its communication with the other bacteria. A bacterium essentially progresses in steps scanning for an environment with a higher nutrient gradient. This strategy of chemotactic movement of virtual bacteria in the problem search space is used in BFOA. When a bacterium gets sufficient food, it grows, increasing in length until, in the presence of favorable environment conditions it breaks and produces an exact replica of itself in a process known as reproduction. Changes in the environment may not always be favorable, for sudden or abrupt changes in the environment can result in the movement of bacteria to some other place or even their destruction. This is the process of elimination and dispersal. Thus, the three processes of chemotaxis, reproduction and elimination- dispersal form the pith of the BFOA. A trial solution represents a bacterium, the optimum solution of which can be obtained by moving on the functional surface. BFOA applications include but are not limited to PWM converter switching, optimization of power converters and control of power converters. Also, the design parameters are presented in Table 1.

Figure 1 depicts the flowchart showing the operation of the proposed boost inverter model along with the topology used. The two DC-DC converters feed a load, connected differentially across them. The output obtained from one converter is phase shifted by 180 with respect to the other to ensure maximum voltage excursion. A DC biased sine wave voltage is obtained at the load. The switches are fed with pulses from the DSpace 1104 setup integrated with Simulink software modelling for the required pulse generation. However, in order to achieve closed loop control, the output voltage is measured by a voltage sensor LEM LV-25P and compared with the preset Vref voltage to obtain the error value, which is then fed into the PI controller. The operating parameters of the above, the optimized proportional and integral constants are obtained using the BFOA. The result is then used to generate the PWM waveforms, which are then stepped up using the Opto-Driver HCPL 3120 to a value as according to the value of Gate voltage required to drive the switches. Thus, the closed loop operation of the BFOABI, with optimized PI constants obtained using BFOA is achieved. The results are then measured using a differential probe and observed on the digital oscilloscope.

The hardware setup of the proposed BFOABI is presented in Figure 2. The experimental setup consists of programmable dc power supply (Promomac 80 V-60 A rating), for resistive in-phase load, rheostat, for non-linear load, universal motor load and a MSO for measurement. For closed loop operation LEM LV25 P voltage sensor is used as a feedback device. Since a differential voltage is to be measured, we require the use of differential probe. Current probes are used to measure the inductor and load currents and are displayed in the MSO. HCPL opto driver assembly is used to step up the gate pulses to a value that is sufficient to drive the switches.

\section{Measurement Results}

Upon testing of the BFOABI model, with parameters as shown in Table 2, steady state linear, line and load

Table 1. The BFOA design parameters.

\begin{tabular}{ccc}
\hline S1 No. & Parameter & Value \\
\hline 1 & Population size & 10 \\
2 & No of iteration & 10 \\
3 & Chemotactic size & 4 \\
4 & Reproduction loop size & 4 \\
5 & Elimination and dispersal loop size & 2 \\
6 & Swim length & 4 \\
7 & Dispersal probability & 0.2 \\
\hline
\end{tabular}




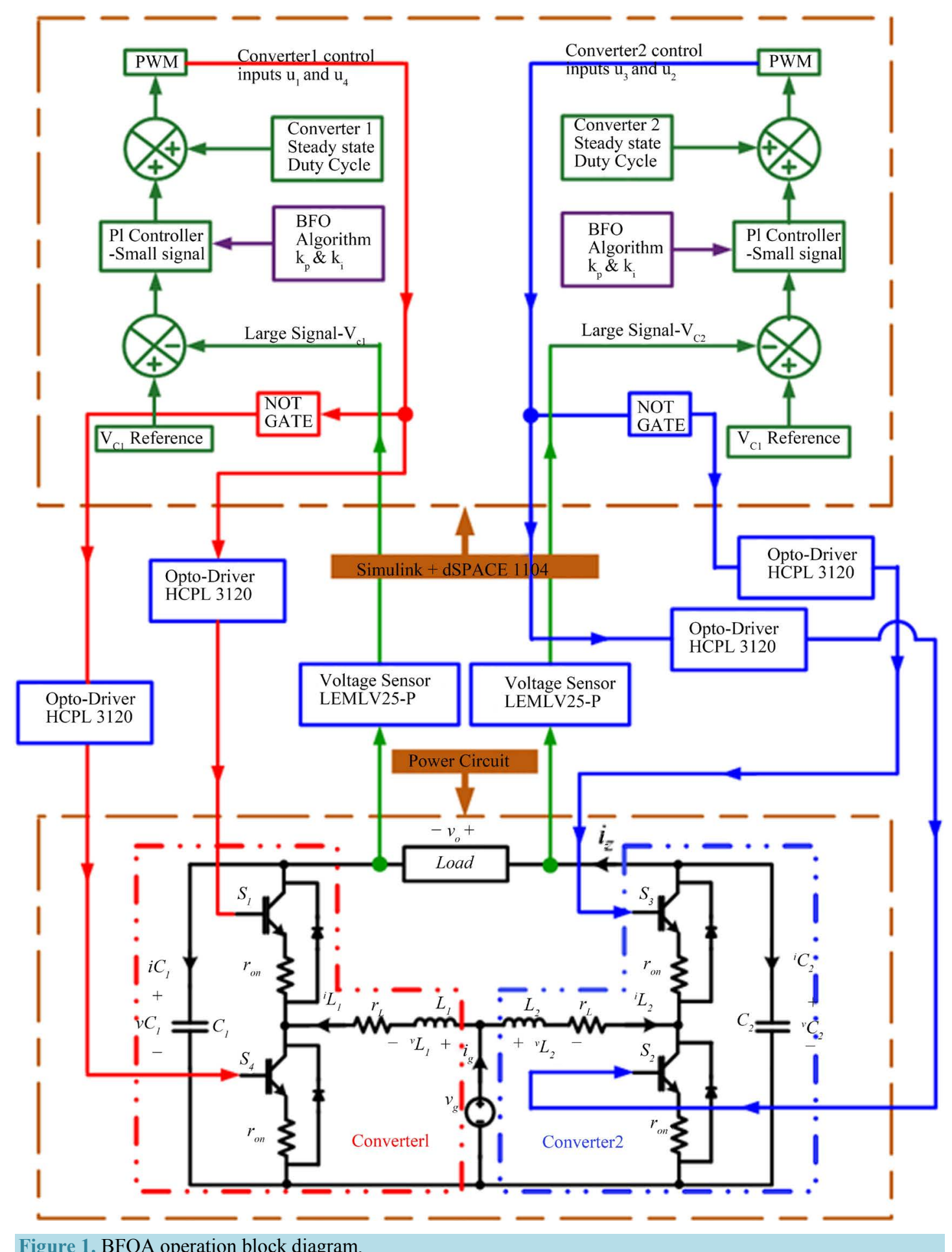

disturbances tests were done on the existing boost inverter model and satisfactory results were obtained. A specific set of $\mathrm{kp}$ and ki values were obtained from simulation to obtain a minimum value for the following parameters: rise time, peak time, settling time and steady state error as given in Table 3. Figure 3 shows the steady state waveform of the two capacitor voltages, $\mathrm{VC} 1$ and $\mathrm{VC} 2$ with the input voltage $\mathrm{Vg}$ and output voltage Vo while Figure 4 additionally indicates the steady state output current Io for a rheostatic load. The following characteristics are worth noticing. First, we can clearly observe that the two capacitor voltages have a phase shift of 
180 degrees between them. The output load voltage is the differential voltage between the two capacitors. Thus, by virtue of the aforementioned phase shift, we ensure a maximum output voltage at all instances.

Second, in accordance with the formula indicated below, the voltages observed are clamped sinusoidal voltages, (i.e.) sinusoidal waveforms with an additional dc voltage bias Vdc.

$$
\begin{gathered}
V_{C 1}=V_{d c}+0.5 V_{m} \operatorname{Sin} \theta \\
V_{C 2}=V_{d c}+0.5 V_{m} \sin \left(\theta-180^{\circ}\right)
\end{gathered}
$$

The steady state inductor currents are also presented in Figure 5. As with the capacitor voltages, the inductor currents are also phase shifted by 180 degrees as per the topology of the Boost inverter used. Varying the line voltage from $36 \mathrm{~V}$ to $33 \mathrm{~V}$ and vice-versa, varying the load from lagging to unity power factor and vice-versa was also done and results have been presented. The output voltage is unaffected despite these load changes, while the current waveform varies as according to the type of load and recovers to the stable sinusoidal fashion within $2 \mathrm{~ms}$. Detailed analysis about the line and load regulation is also done in the subsections below.

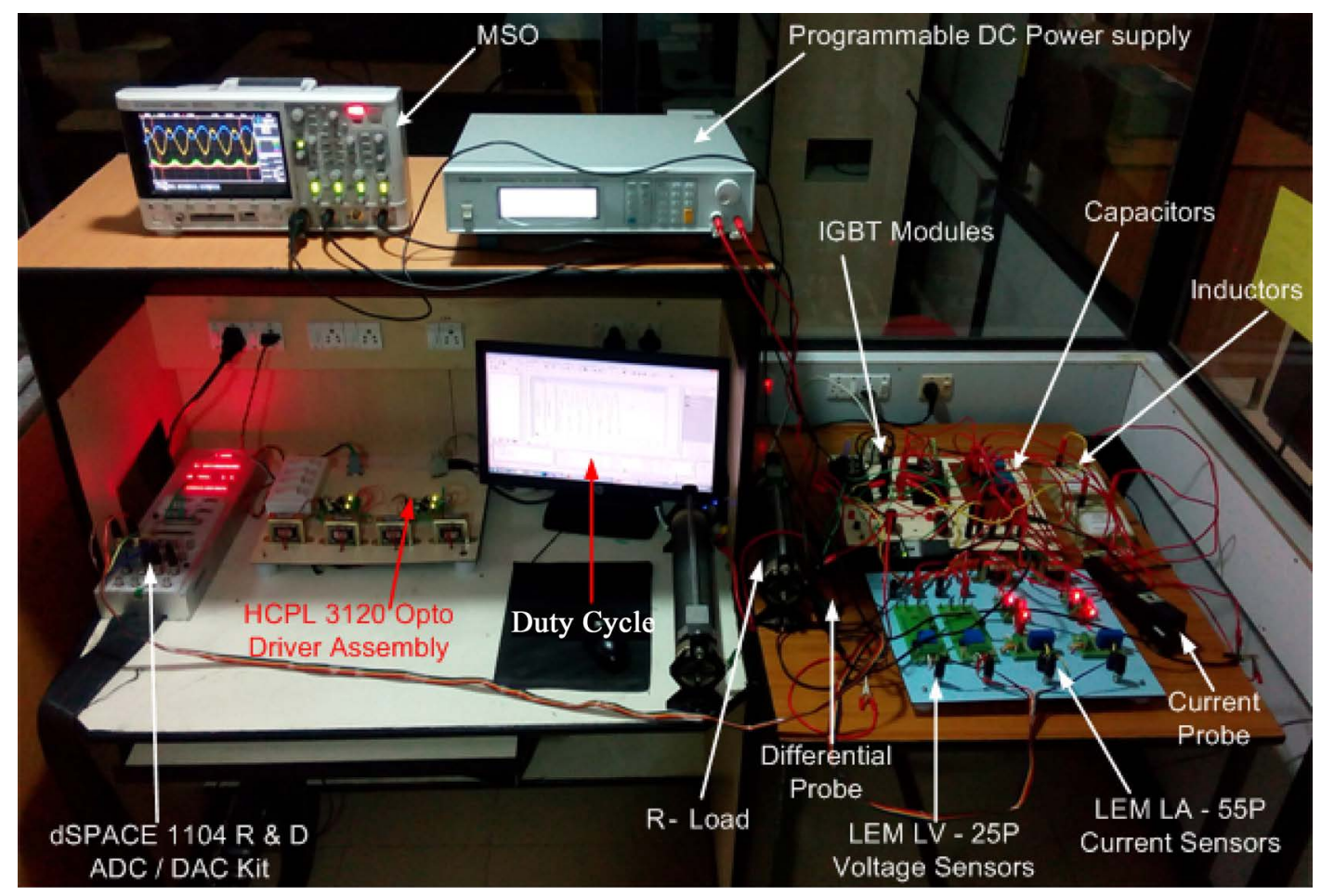

Figure 2. BFOA based boost inverter hardware setup of experiment.

Table 2. Boost inverter design parameters.

\begin{tabular}{ccc}
\hline Sl No. & Parameter & Value \\
\hline 1 & Input dc voltage, $\mathrm{V}_{\mathrm{g}}$ & $36 \mathrm{~V}$ \\
2 & Capacitors, $\mathrm{C} 1$ and $\mathrm{C} 2$ & $20 \mu \mathrm{F}$ \\
3 & Output ac voltage, $\mathrm{V}_{\mathrm{o}}$ & $110 \mathrm{~V}_{\text {rms }}$ \\
4 & Load resistor, $\mathrm{R}$ & 220 \\
5 & Switching frequency, $\mathrm{f}_{\mathrm{s}}$ & $20,000 \mathrm{~Hz}$ \\
6 & Real time interfacing kit & dSPACE-1104 \\
7 & Dual IGBT modules, $\mathrm{S}_{1}$ to $\mathrm{S}_{4}$ & $\mathrm{CM} 75 \mathrm{DU}-12 \mathrm{H}$ \\
8 & Voltage Sensor, LEM LV $25 \mathrm{P}$ & $500 \mathrm{~V}$ \\
9 & Inductors, $\mathrm{L}_{1}$ and $\mathrm{L}_{2}$ & $200 \mathrm{H}$ with 0.3 parasitic resistance \\
\hline
\end{tabular}


Table 3. Optimized parameters from BFOA.

\begin{tabular}{cccccccc}
\hline S1 No. & Iteration & $\mathrm{k}_{\mathrm{p}}$ & $\mathrm{k}_{\mathrm{i}}$ & $\mathrm{M}_{\mathrm{p}}$ & $\mathrm{E}_{\mathrm{ss}}$ & $\mathrm{t}_{\mathrm{r}}$ & $\mathrm{t}_{\mathrm{s}}$ \\
\hline 1 & 50 & $3.756 \mathrm{e}^{-5}$ & $3.595 \mathrm{e}^{-5}$ & $2.1 \mathrm{e}^{-8}$ & 0.414 & 0.00562 & 0.017 \\
\hline
\end{tabular}

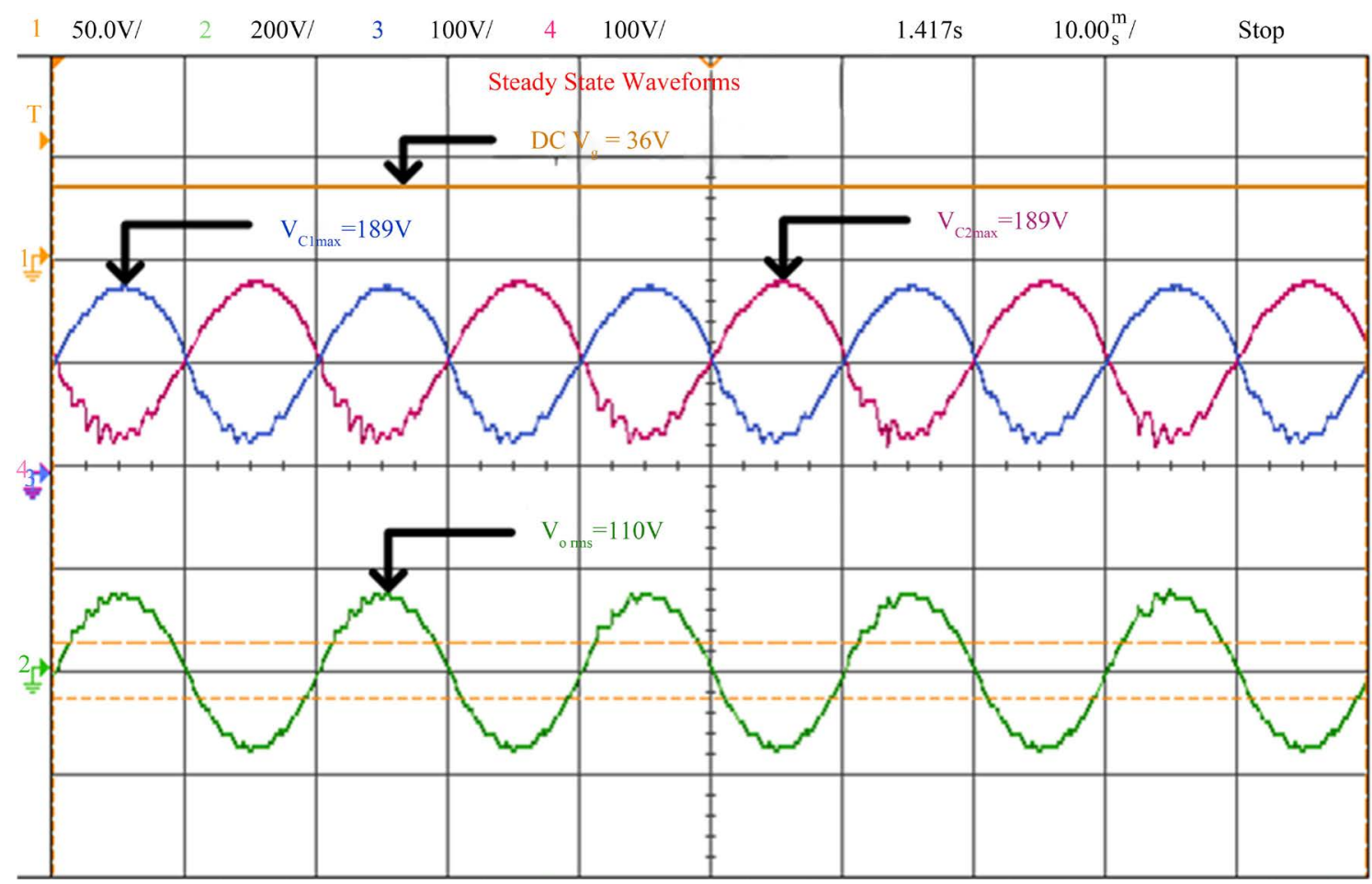

Figure 3. Steady state $\mathrm{V}_{\mathrm{g}}, \mathrm{V}_{\mathrm{Cl}}, \mathrm{V}_{\mathrm{C} 2}, \mathrm{~V}_{\mathrm{o}}$ waveforms.

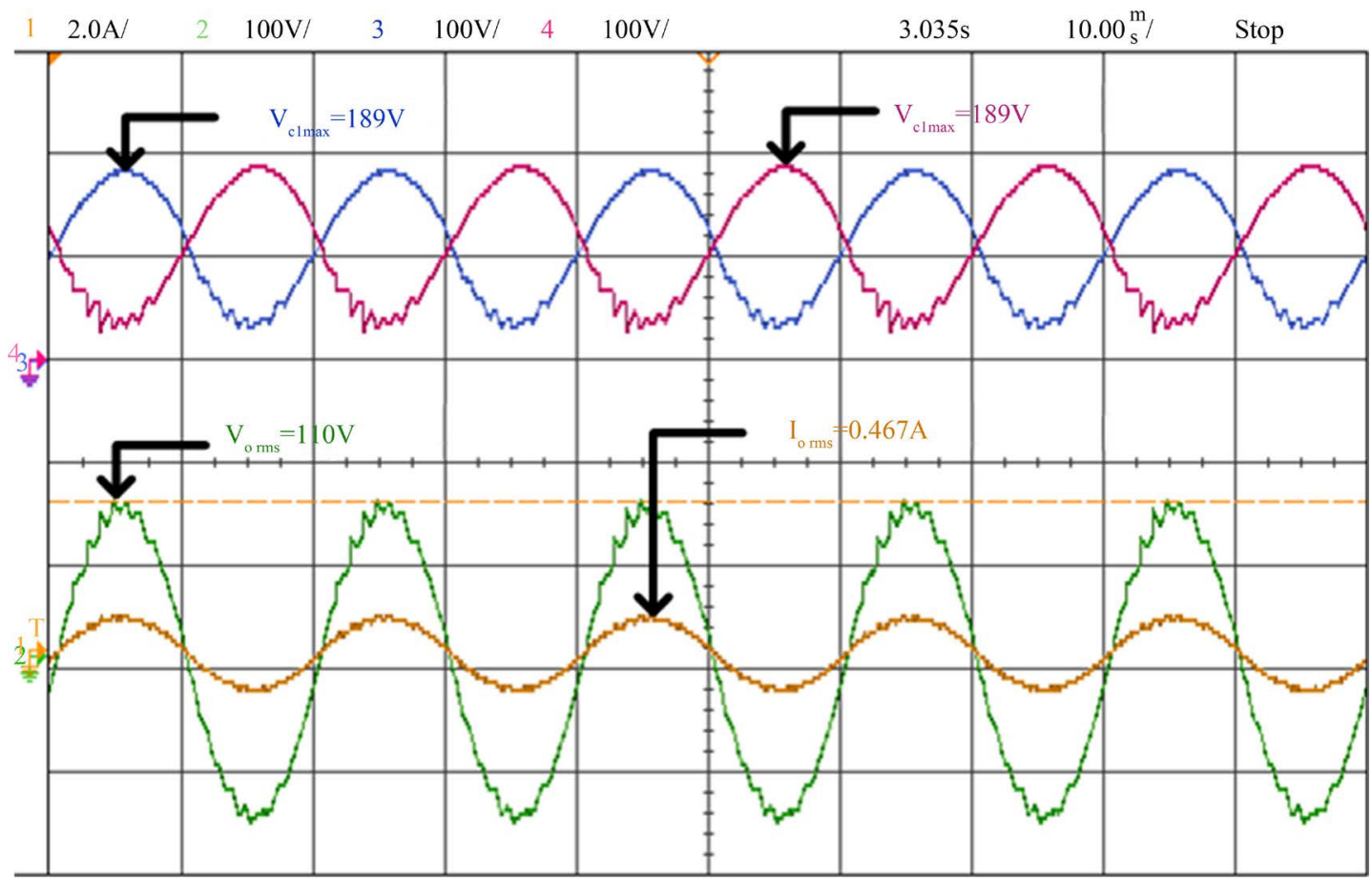

Figure 4. Steady state $\mathrm{V}_{\mathrm{C} 1}, \mathrm{~V}_{\mathrm{C} 2}, \mathrm{~V}_{\mathrm{o}}, \mathrm{I}_{\mathrm{o}}$ waveforms. 


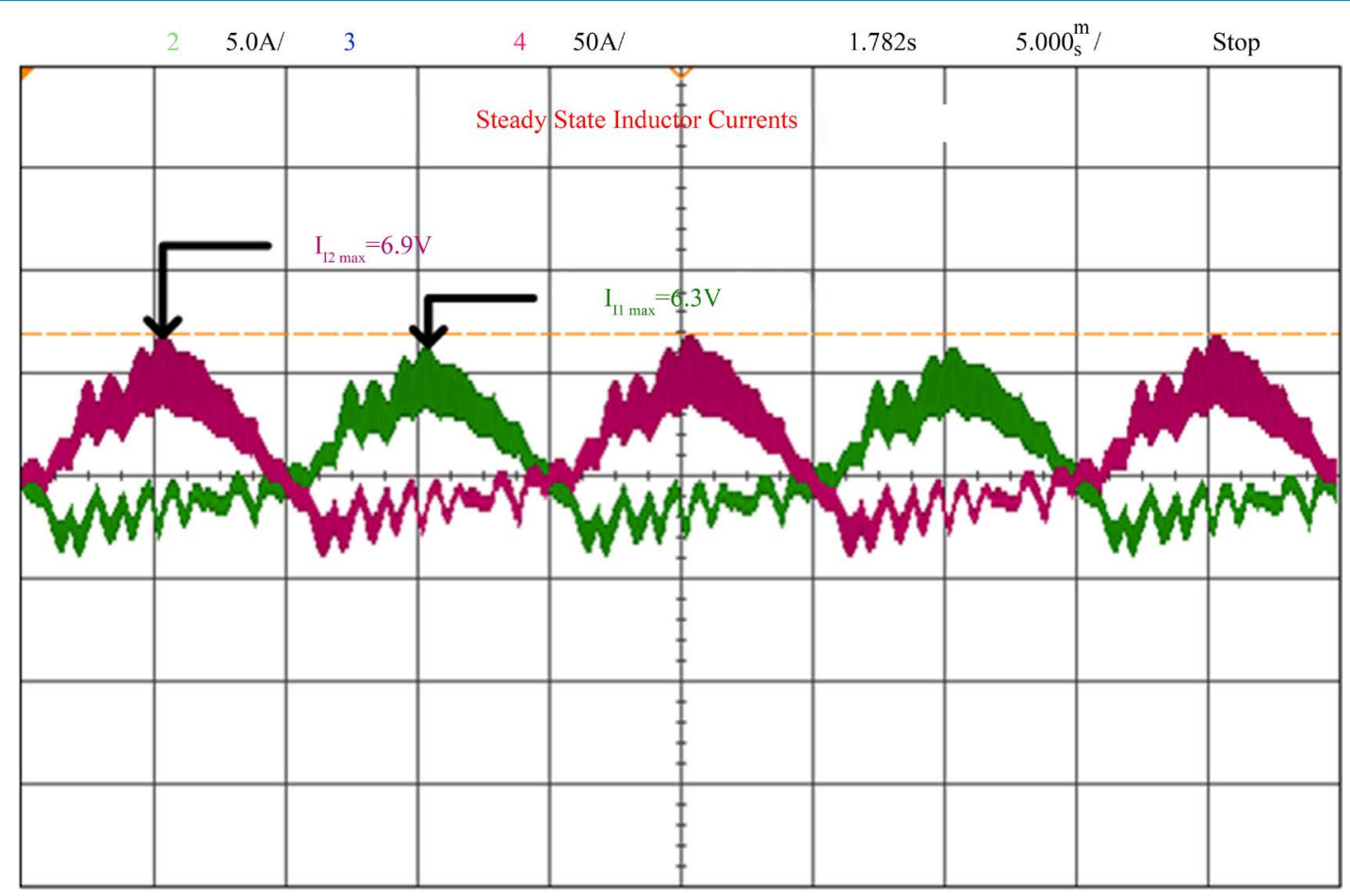

Figure 5. Steady state inductor current waveforms.

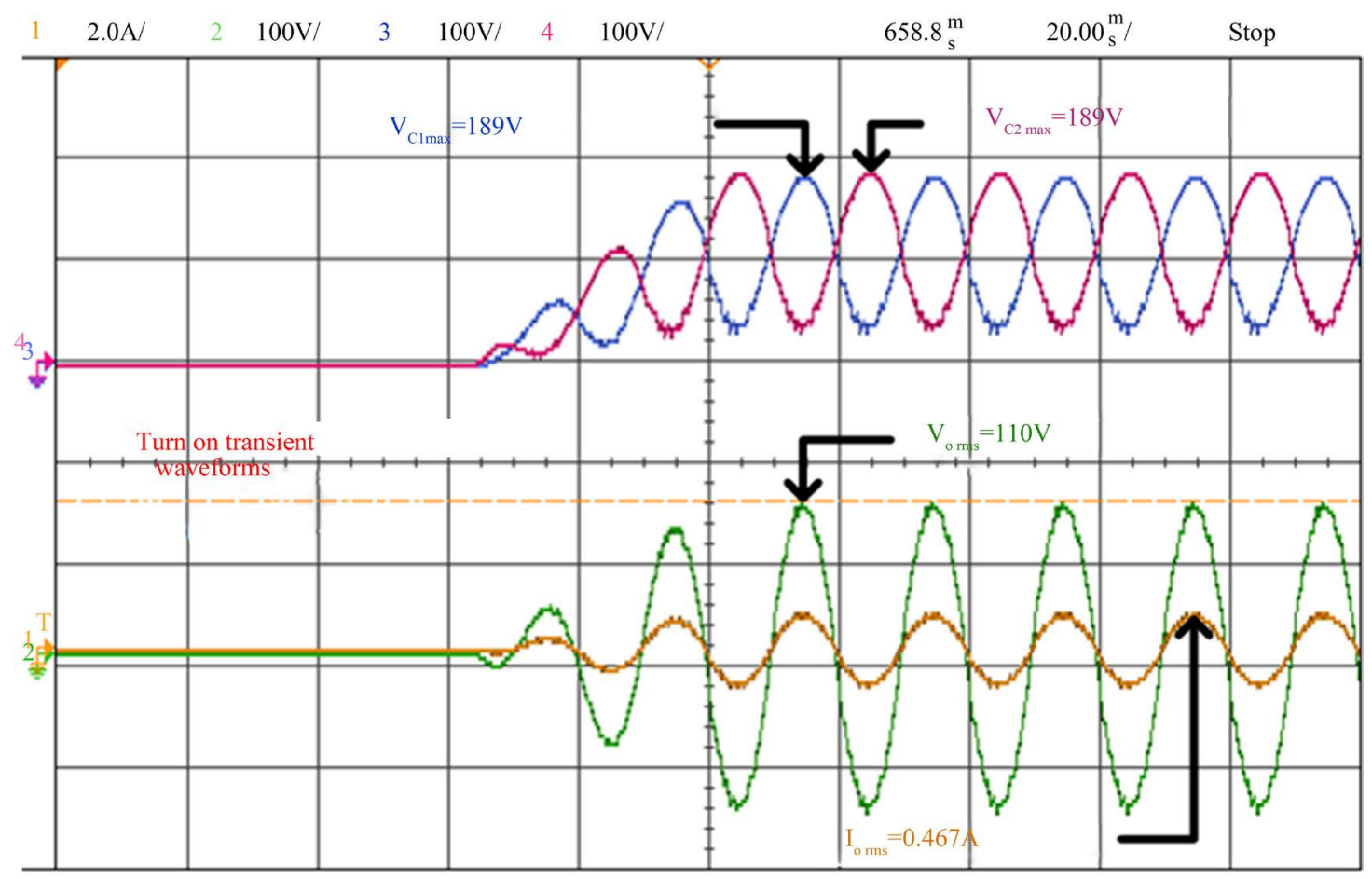

Figure 6. Supply turn on transient waveforms.

Figure 6 shows the initial transient response with the two capacitor voltages and the output voltage and current while Figure 7 represents the turn off transient waveforms of the same parameters. We must note that our proposed model, due to apt topology, control parameters etc., eliminates all the in-rush current or voltage spikes successfully. The same smooth waveform can be seen during turn off transients too. Once the steady state is 
reached after the initial build up, the desired waveform fashions are obtained. The capacitor voltages are opposite in phase to each other as required. The output voltage waveform is also observed to be in phase with the current waveform. The value of capacitor voltages follows the formulae provided in Equation (4) and Equation (5).

\subsection{Line Regulation}

When the inverter input voltage is being stepped down from 36 to $33 \mathrm{~V}$ as shown in Figure 8, it is observed that

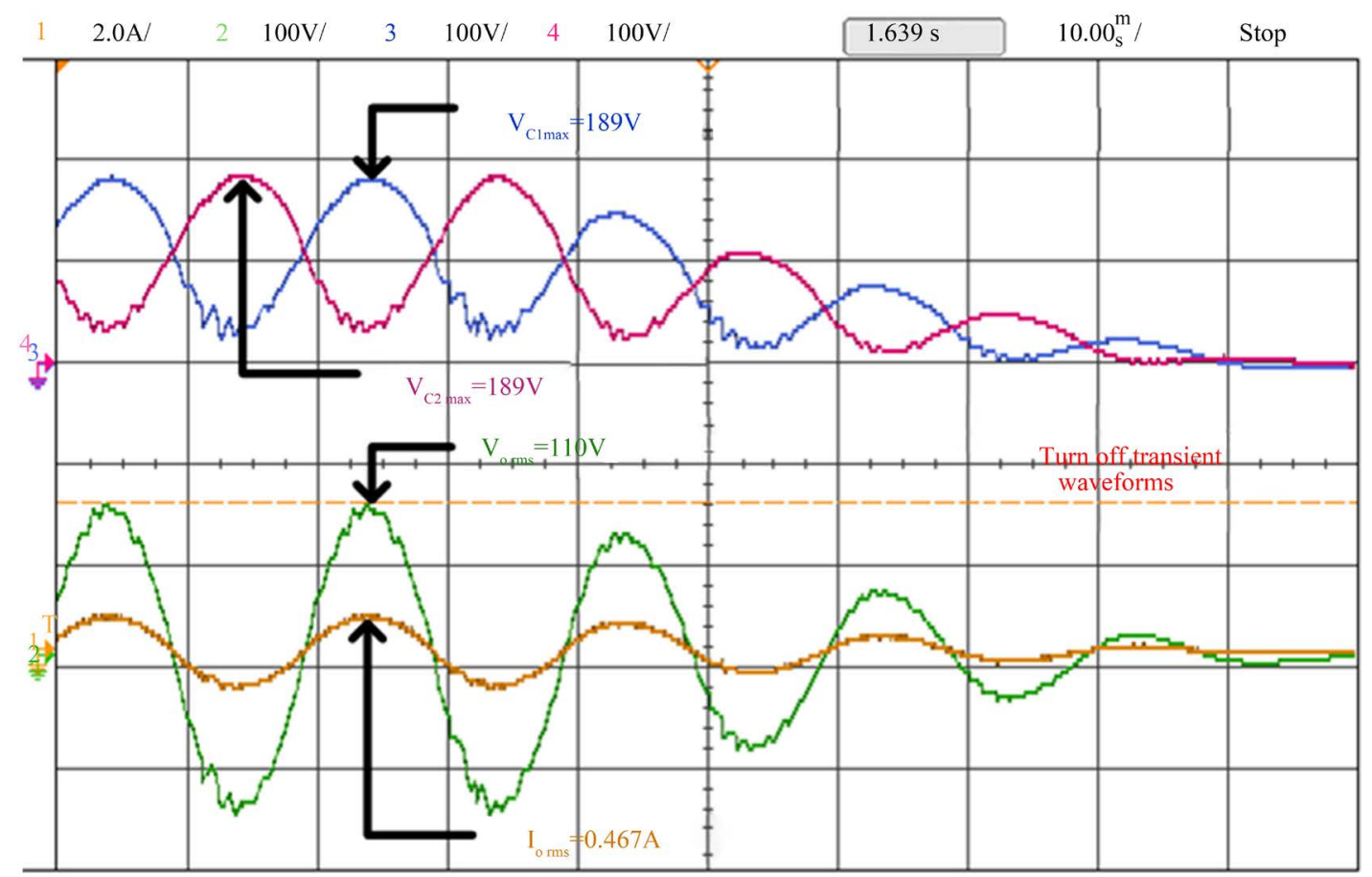

Figure 7. Supply turn off transient waveforms.

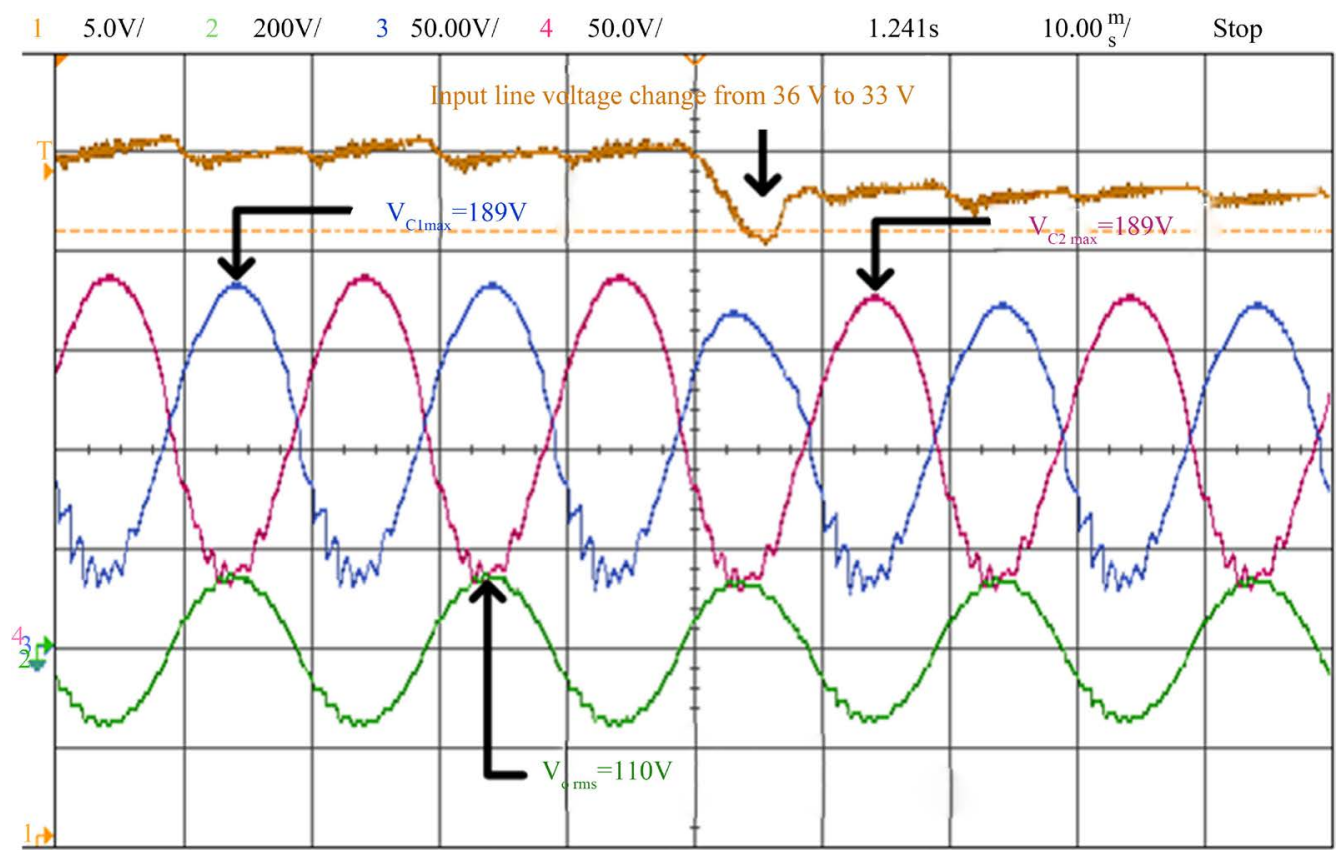

Figure 8. Supply line disturbance step down from $36 \mathrm{~V}$ to $33 \mathrm{~V}$. 
the output voltage is resilient to this change while output current reaches steady state within a fraction of $2 \mathrm{~ms}$ and we get a waveform with very good quality. The rise time, peak time, settling time and steady state error attains a minimum value. The resilience can be attributed to the successful closed loop control method employed incorporating the BFOA which selects the optimal operating point in a very small duration of time as evidenced by the results presented. Similar results can be observed when the line voltage is stepped up. The results of the same are presented in Figure 9.

\subsection{Load Regulation}

When the system is subjected to a sudden change in load from a lagging power factor to a unity power factor load, it is being observed that the output current reaches steady state within a fraction of time, 2 ms, and the corresponding graph is being shown in Figure 10. Similarly when a change of load was from unity power factor

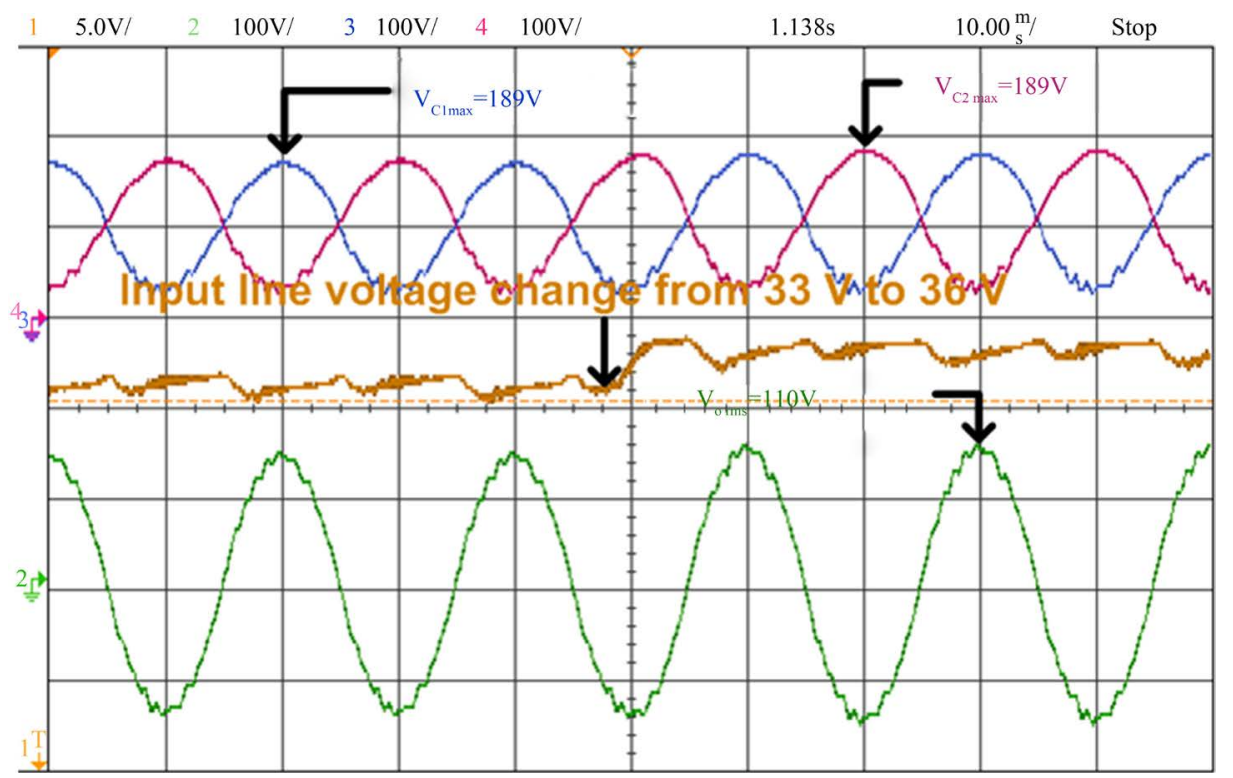

Figure 9. Supply line disturbance step up from $33 \mathrm{~V}$ to $36 \mathrm{~V}$.

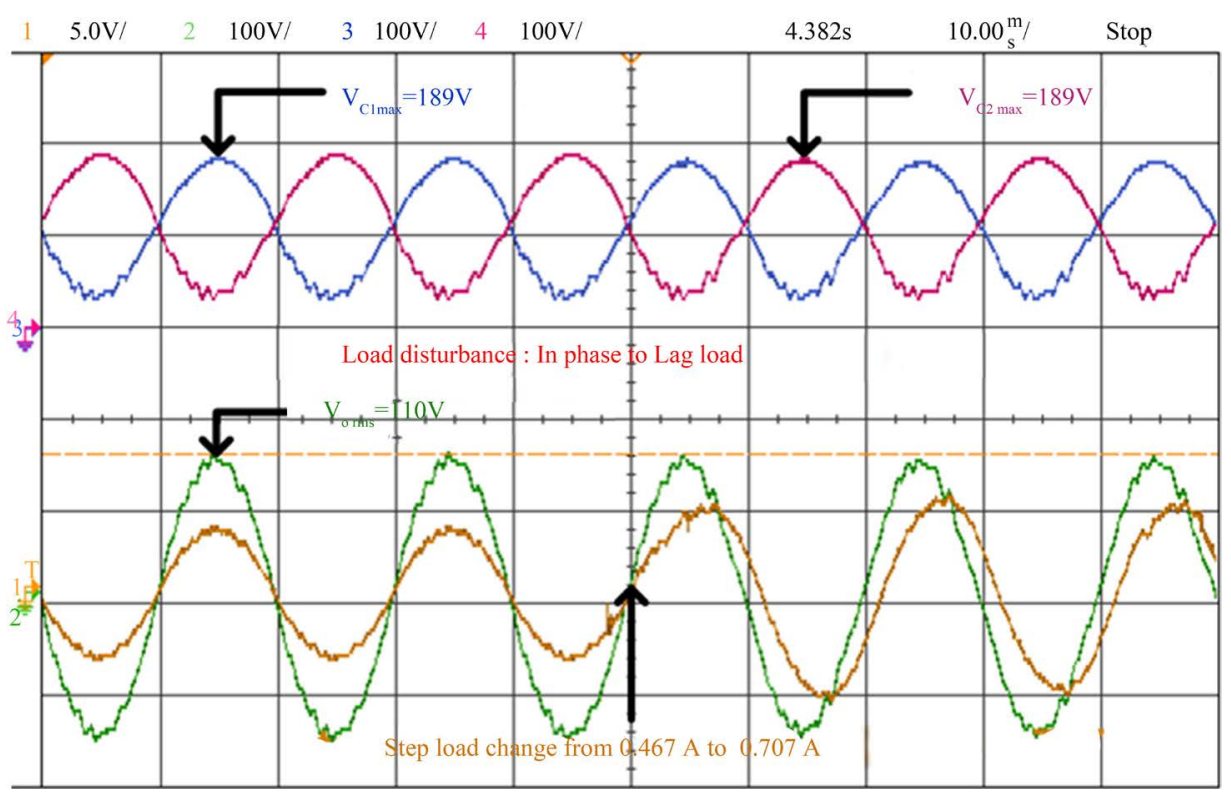

Figure 10. Load disturbance from in phase to lag load. 
to a lagging load was done, we observed that the same desirable waveform pattern was observed as was with the case of line disturbance. The results of which are represented in Figure 11. The BFOABI system reaches steady state swiftly and the above mentioned parameters attain a desirable value. Thus, the mentioned primary objective is being met.

\subsection{THD Performance Results}

As proposed in this paper, from Figure 12, we can see that the THD value is $4.22 \%$. THD value is a good esti-

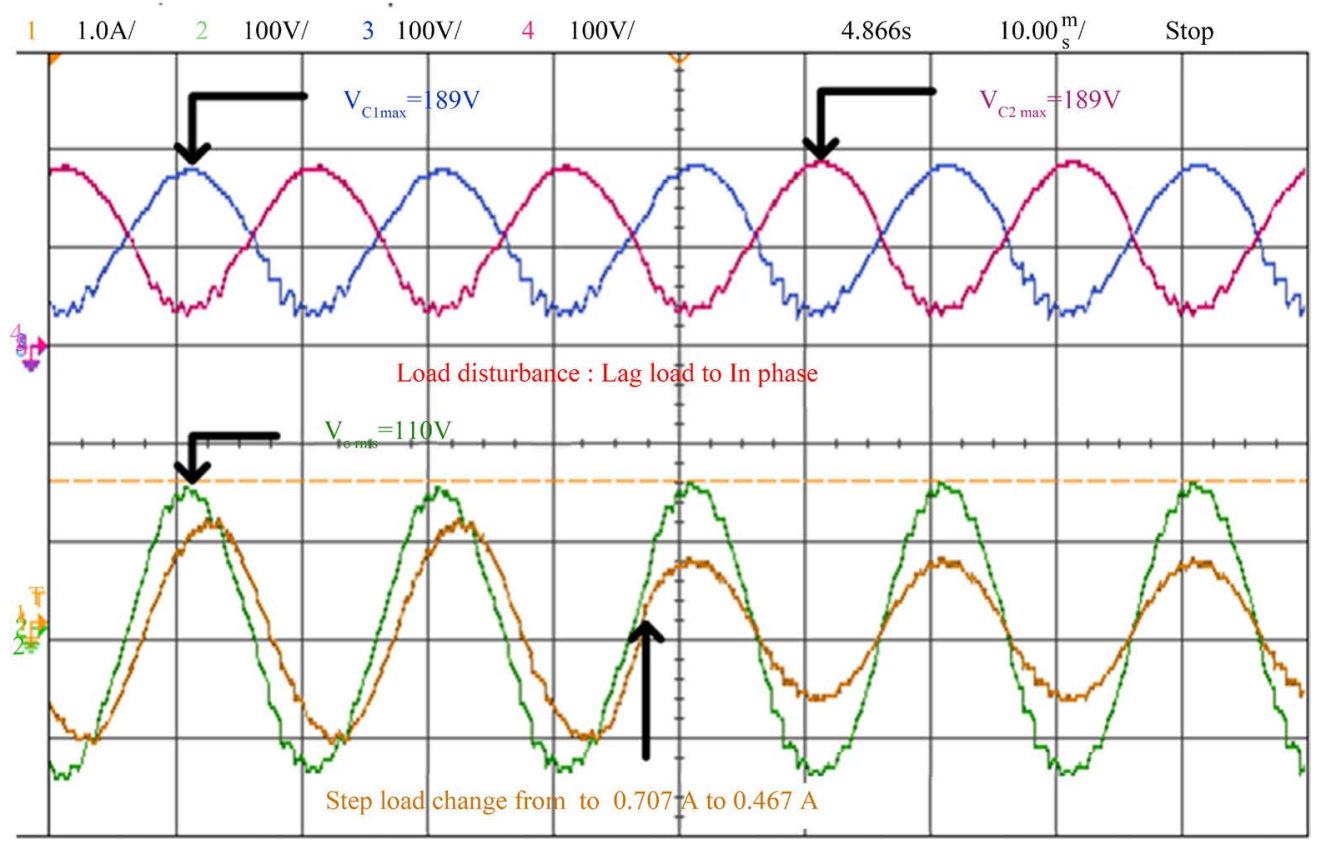

Figure 11. Load disturbance from lag load to in phase load.

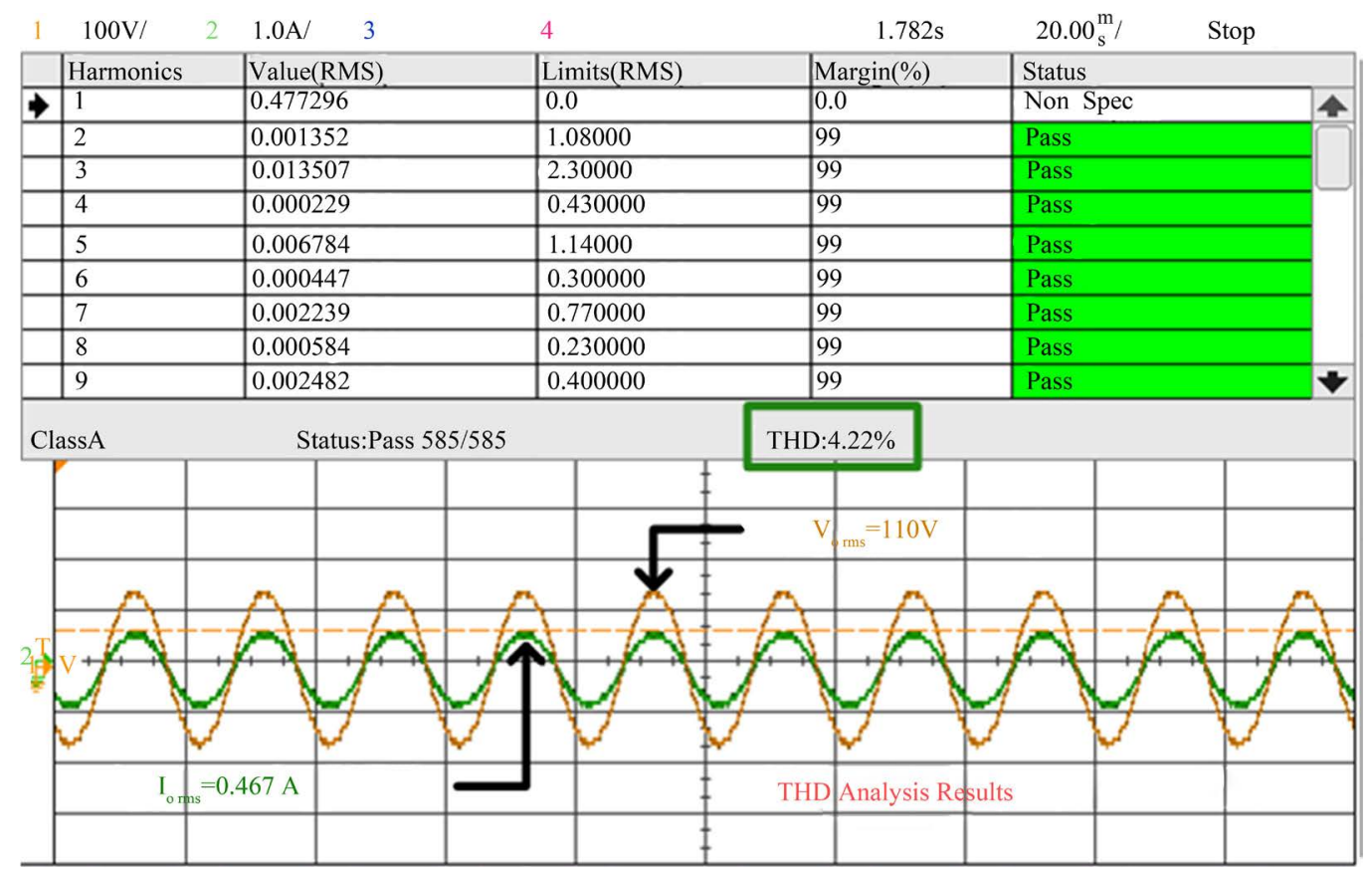

Figure 12. THD performance analysis result. 
mator of the reliability of output voltage and is an important factor for determining industrial applicability of this setup. the result obtained by our proposed model comfortably meets the Class A standard prescribed by IEEE, (i.e.) $\leq 5 \%$, for the rated voltage of $36 \mathrm{~V}$ to $110 \mathrm{Vrms}$. Generally even harmonics are zero for inverters, however odd harmonics that dominate, 3rd, 5th, 9th harmonics are also well below the permissible limit, thereby earning a status of PASS on the THD testing done. This result was observed for a variety of loads, rheostatic (as shown in Figure 4) lamp load and even for the universal motor load used. The desirable results observed are due to the use of high frequency ferrite core inductors, metallized thin film capacitors, optimization of the parameters kp and ki which result in appropriate duty cycle values for the switches, thereby reducing the harmonics in output for any load used.

\section{Conclusion}

BFOA based Boost Inverter was presented. DC to AC conversion was achieved in a single stage, incorporating closed loop voltage control techniques. Bacterial Foraging Algorithm was successfully utilized to obtain the optimal values of $\mathrm{kp}$ and ki. BFOA algorithm, as proposed, improved the system response of the boost inverter system, reducing rise time, settling time, peak overshoot and steady state error, thereby successfully fulfilling the objective of obtaining desirable time domain system responses. As per IEEE standards, the THD value was observed to be much lower than traditional topology inverters. As evidenced by our results, even when subjected to line and load disturbances, output voltage reached steady state within a time duration of 2 milliseconds exhibiting stability and an ability to withstand the disturbances in any system in which it is utilized. Thus, the proposed system is suitable for all sorts of grid connected and renewable energy applications. For future research, efforts to implement the system with a PV array input can be attempted.

\section{Acknowledgements}

We thank the Editor and the referee for their comments. Research of I. Gnanambal is funded by the National Science Foundation grant DMS 1322353. This support is greatly appreciated.

\section{References}

[1] Caceres, R., et al. (1999) A Boost DC-AC Converter: Analysis, Design, and Experimentation. IEEE Transactions on Power Electronics, 14, 134-141.

[2] Vazquez, N., Alvarez, J., Aguilar, C. and Arau, J. (1998) Some Critical Aspects in Sliding Mode Control Design for the Boost Inverter. The 6th IEEE International Power Electronics Congress, CIEP 98, Morelia, 12-15 October 1998, 76-81. http://dx.doi.org/10.1109/ciep.1998.750663

[3] Albea, C., Canudas-de-Wit, C. and Gordillo, F. (2007) Adaptive Control of the Boost DC-AC Converter. IEEE 22nd International Symposium on Intelligent Control, ISIC, Singapore, 1-3 October 2007, 611-616. http://dx.doi.org/10.1109/cca.2007.4389299

[4] Albea, C., Gordillo, F. and Canudas-de-Wit, C. (2008) Adaptive Control of the Boost Inverter with Load RL. IFAC Proceedings Volumes, 41, 3316-3321. http://dx.doi.org/10.3182/20080706-5-kr-1001.00563

[5] Aracil, J., et al. (2002) On the Control of Oscillations in DC-AC Converters. 0-7803-7474-610 IEEE.

[6] Albea, C. and Gordillo, F. (2007) Control of the Boost DC-AC Converter with RL Load by Energy Shaping. The 46th IEEE Conference on Decision and Control, New Orleans, 12-14 December 2007. http://dx.doi.org/10.1109/cdc.2007.4434621

[7] Albea, C., Gordillo, F. and Aracil, J. (2006) Control of the Boost DC-AC Converter by Energy Shaping. The 32nd Annual Conference on IEEE Industrial Electronics, IECON, Paris, 6-10 November 2006, 754-759. http://dx.doi.org/10.1109/iecon.2006.347263

[8] Bowes, S.R. and Holliday, D. (2007) Optimal Regular-Sampled PWM Inverter Control Techniques. IEEE Transactions on Industrial Electronics, 54, 1547-1559. http://dx.doi.org/10.1109/TIE.2007.894767

[9] Sharma, V., Pattnaik, S.S. and Garg, T. (2012) A Review of Bacterial Foraging Optimization and Its Applications. National Conference on Future Aspects of Artificial intelligence in Industrial Automation, NCFAAIIA, 9-12.

[10] Passino, K.M., et al. (2010) Bacterial Foraging Optimization. International Journal for Swarm Intelligence Research, 1, 1-16. http://dx.doi.org/10.4018/jsir.2010010101

[11] Jha, K., et al. (2015) High-Quality Sine Wave Generation Using a Differential Boost Inverter at Higher Operating Frequency. IEEE Transactions on Industry Applications, 51, No. 1. http://ieeexplore.ieee.org/xpls/abs all.jsp?arnumber=6828776 